\title{
Evidence for cognitive-behavioral strategies improving dyspnea and related distress in COPD
}

This article was published in the following Dove Press journal: International Journal of Chronic Obstructive Pulmonary Disease 24 September 2013

Number of times this article has been viewed

\author{
Anna Norweg' \\ Eileen G Collins ${ }^{2,3}$ \\ 'Department of Occupational Therapy, \\ College of Applied Health Sciences, \\ University of Illinois at Chicago (UIC), \\ Chicago, IL, USA; ${ }^{2}$ Department of \\ Biobehavioral Health Science, College \\ of Nursing, University of Illinois at \\ Chicago (UIC), Chicago, IL, USA; \\ ${ }^{3}$ Rehabilitation Research and \\ Development (RR\&D), Edward Hines \\ Jr.VA Hospital, Hines, IL, USA
}

Background: Dyspnea is a complex, prevalent, and distressing symptom of chronic obstructive pulmonary disease (COPD) associated with decreased quality of life, significant disability, and increased mortality. It is a major reason for referral to pulmonary rehabilitation.

Methods: We reviewed 23 COPD studies to examine the evidence for the effectiveness of cognitive-behavioral strategies for relieving dyspnea in COPD.

Results: Preliminary evidence from randomized controlled trials exists to support cognitivebehavioral strategies, used with or without exercise, for relieving sensory and affective components of dyspnea in COPD. Small to moderate treatment effects for relieving dyspnea were noted for psychotherapy (effect size $[\mathrm{ES}]=0.08-0.25$ for intensity; $0.26-0.65$ for mastery) and distractive auditory stimuli ( $E S=0.08-0.33$ for intensity; 0.09 to -0.61 for functional burden). Small to large dyspnea improvements resulted from yoga ( $E S=0.2-1.21$ for intensity; 0.67 for distress; 0.07 for mastery; and -8.37 for functional burden); dyspnea self-management education with exercise ( $\mathrm{ES}=-0.14$ to -1.15 for intensity; -0.62 to -0.69 for distress; 1.04 for mastery; $0.14-0.35$ for self-efficacy); and slow-breathing exercises ( $E S=-0.34$ to -0.83 for intensity; -0.61 to -0.80 for distress; and 0.62 for self-efficacy). Cognitive-behavioral interventions may relieve dyspnea in COPD by (1) decreasing sympathetic nerve activity, dynamic hyperinflation, and comorbid anxiety, and (2) promoting arterial oxygen saturation, myelinated vagus nerve activity, a greater exercise training effect, and neuroplasticity.

Conclusion: While evidence is increasing, additional randomized controlled trials are needed to evaluate the effectiveness of psychosocial and self-management interventions in relieving dyspnea, in order to make them more available to patients and to endorse them in official COPD, dyspnea, and pulmonary rehabilitation practice guidelines. By relieving dyspnea and related anxiety, such interventions may promote adherence to exercise programs and adaptive lifestyle change.

Keywords: chronic obstructive pulmonary disease, dyspnea, anxiety, slow breathing, distractive auditory stimuli, self-management

\section{Introduction}

Alleviating dyspnea is a primary goal of pulmonary rehabilitation (PR) and selfmanagement (SM) interventions in chronic obstructive pulmonary disease (COPD). ${ }^{1}$ Dyspnea is a "subjective experience of breathing discomfort." ${ }^{2}$ It is perceived via two main afferent neural pathways: (1) chemoreceptors and vagal $\mathrm{C}$ fibers from the lung parenchyma and airways, and (2) chest wall mechanoreceptors and vagal stretch receptors, which are subsequently processed in the insular cortex and corticolimbic system. ${ }^{3}$ The insula appears to have a primary role in the perception of dyspnea based on its interoception function. The insula works closely with the amygdala and anterior
Correspondence: Anna Norweg University of Illinois at Chicago (UIC), College of Applied Health Sciences, Department of Occupational Therapy, 1919 W Taylor Street, (329 AHSB), Chicago, IL 606I2, USA

Email anorweg@uic.edu 
cingulated cortex to modulate dyspnea-related attention and affect based on arousal and valence. ${ }^{4}$

There can be remarkable variation between self-reported dyspnea and the degree of pulmonary obstruction. ${ }^{5,6}$ Dyspnea includes both conscious awareness of physical sensation intensity and affective judgment and response..$^{7,8}$ The American Thoracic Society's (ATS) 2012 practice guidelines ${ }^{2}$ divide dyspnea into three domains: sensory perceptual experience, affective distress, and symptom impact or burden. Dyspnea can be strongly influenced by negative affectivity, anxiety, and distress. ${ }^{5,8-12}$ Anxiety may contribute to hyper-perception of dyspnea or an exaggerated or distorted perception relative to the severity of pulmonary dysfunction. ${ }^{7}, 13$ A distressing emotional response to dyspnea may lead to a heightened attention to breathing, inducing further anxiety and causing avoidance behavioral responses. ${ }^{7}$ Dyspnea has been shown to be a better predictor of mortality than pulmonary function (forced expiratory volume in 1 second $\left.\left[\mathrm{FEV}_{1}\right]\right){ }^{14}$

Patients with COPD have been shown to experience significantly increased comorbid psychological distress and anxiety compared with the general population ${ }^{15-19}$ and to have higher sympathetic nerve activity and parasympathetic dysfunction. ${ }^{20,21}$ It is estimated that the prevalence of anxiety is between $10 \%$ and $19 \%$ in stable COPD and between $9 \%$ and $58 \%$ in patients with unstable COPD resulting from a recent exacerbation. ${ }^{16}$

There is strong evidence supporting the effectiveness of PR that consists of at least 4 weeks of exercising training in improving dyspnea in adults with COPD. ${ }^{22}$ PR practice guidelines recommend a program of exercise training (ET) for the muscles of ambulation as a mandatory component of PR for patients with COPD. ${ }^{22}$ To date, there is little understanding of how pulmonary rehabilitation works to relieve dyspnea in patients with COPD and how much improvements relate to a conditioning effect, desensitization to the sensory experience, decreased sympathetic activity, and improved self-efficacy. ${ }^{2,23}$

While, based on strong evidence, ET is considered an essential component of PR, PR is not just limited to ET, ${ }^{23}$ and also includes collaborative psychosocial, behavioral, and SM interventions integrated into long-term COPD disease management. ${ }^{22,24}$ The evidence supporting these adjunctive therapies is weaker due to inconsistency in the research findings and variability in the quality of the studies. ${ }^{22}$ The effectiveness of non-exercise and non-pharmacological COPD treatment components in alleviating dyspnea in COPD is not well known. More focused research is needed to determine whether adjunctive therapies to exercise are effective in relieving dyspnea in PR. The best ways to maintain PR gains post-discharge have also not been well established.

Because dyspnea is a symptom, it can only be measured by patient self-report. Measuring the affective component of dyspnea, in addition to the sensory component (intensity), is important to more comprehensively evaluate the outcomes of PR and cognitive-behavioral interventions (see Table 1 for a summary of dyspnea assessments, their minimal clinical important difference (MCID) if known, and reference citations).

Table I Dyspnea assessments used in review studies

\begin{tabular}{|c|c|c|}
\hline Instrument name & Constructs & MCID \\
\hline Borg Breathlessness Scale (Borg) ${ }^{64}$ & Dyspnea intensity & I.0 unit \\
\hline Borg Dyspnea Distress Scale $\left(\text { Borg }^{\mathrm{DD}}\right)^{25,65}$ & Dyspnea distress & I.0 unit \\
\hline Breathlessness Beliefs Questionnaire ${ }^{66}$ & Dyspnea-related anxiety: somatic and activity avoidance beliefs & Not known \\
\hline Chronic Respiratory Disease Questionnaire (CRQ) ${ }^{67-69}$ & $\begin{array}{l}\text { Dyspnea intensity with activities (dyspnea scale, CRQ-D); } \\
\text { dyspnea-related anxiety (mastery scale, CRQ-M) }\end{array}$ & 0.5 per item \\
\hline COPD Self-Efficacy Scale (CSES) ${ }^{70}$ & Dyspnea self-efficacy & Not known \\
\hline Dyspnea Management Questionnaire (DMQ) $)^{39,71,72}$ & $\begin{array}{l}\text { Dyspnea intensity with activities; dyspnea-related anxiety; } \\
\text { activity avoidance; self-efficacy }\end{array}$ & Not known \\
\hline Interpretation of Breathing Problems Questionnaire (IBPQ) ${ }^{73}$ & Dyspnea-related anxiety; catastrophic thoughts & Not known \\
\hline Modified Medical Research Council Dyspnea Scale (mMRC)' & Dyspnea impact or burden & Not known \\
\hline Self-Efficacy for Managing Shortness of Breath (SEMSOB) ${ }^{74}$ & Dyspnea self-efficacy & Not known \\
\hline St George’s Respiratory Questionnaire (SGRQ) $)^{2,75}$ & Dyspnea impact or burden (activity scale: SGRQ-A) & 4 units \\
\hline Transition Dyspnea Index (TDI) ${ }^{76}$ & Dyspnea impact or burden & I.0 unit \\
\hline $\begin{array}{l}\text { University of California, San Diego Shortness } \\
\text { of Breath Questionnaire (SOBQ) })^{64,77}\end{array}$ & Dyspnea intensity with activities & 5 units \\
\hline Visual Analog Scale - Unpleasantness (VAS-U) ${ }^{64,62}$ & Dyspnea affect & $10-20$ units \\
\hline Visual Analog Scale - Dyspnea Distress (VAS-DD), Dyspnea & Dyspnea distress; dyspnea-related anxiety; dyspnea intensity & 10-20 units \\
\hline Anxiety (VAS-DA), shortness of breath (VAS-SOB) $)^{54,64}$ & & \\
\hline
\end{tabular}

Abbreviations: MCID, minimal clinical important difference; COPD, chronic obstructive pulmonary disease; $D$, dyspnea scale; M, mastery scale; A, activity scale. 
This review was conducted to critique the evidence for current adjunctive psychosocial therapies used both during and after PR to specifically manage and relieve the sensory and affective components of dyspnea in patients with COPD. For this review, we focused on cognitivebehavioral and SM therapies that could complement ET and pharmacologic interventions in PR. Only COPD randomized controlled trials (RCTs) that included at least one outcome measure of dyspnea were included in this review. The review focused on studies published between 1996 and 2013. The studies were analyzed and grouped into the following categories: meditation, cognitive-behavioral therapy (psychotherapy), breathing exercises, dyspnea SM education, and distractive auditory stimuli (DAS). Given the wide scope of this review, a systematic review was not conducted.

\section{Meditation}

Six mind-body meditation studies met our inclusion criteria, with sample sizes ranging between 10 and 158, and COPD severity levels varying considerably between the groups from mild to very severe (see Table 2). Two studies showed trends in effectively reducing dyspnea distress (the Borg and the Chronic Respiratory Disease Questionnaire - Modified [CRQ-M]) post-intervention following Iyengar yoga and Tai Chi interventions compared with usual care control groups $(P=0.07-0.08) .{ }^{25,26}$ An additional study found within-group effects for reducing functional burden of dyspnea (St George's Respiratory Questionnaire - Activity scale [SGRQ-A]) following a 3-month yoga breathing intervention but not in the control group $(P<0.01){ }^{27}$ Only one Tai Chi study conducted a follow up evaluation post-intervention at 6 months and found no significant differences for dyspnea when combining Tai Chi with PR. ${ }^{28}$ However, the mean change scores at 6 months for the group receiving Health Qigong Tai Chi plus PR for CRQ dyspnea and CRQ mastery exceeded the MCID scores, while the mean change scores within the comparison PR group did not. ${ }^{28}$

In contrast, Mularski et $\mathrm{al}^{29}$ identified no differences between or within groups for dyspnea following an 8-week group "Mindfulness-Based Breathing Therapy" (MBBT) intervention when compared with a support group. Of note, this study suffered from an especially high drop-out rate of $43 \%$ after randomization. Also, an RCT by Chan et a ${ }^{30}$ of a 3-month Tai Chi Qigong (TCQ) intervention found no effects of TCQ or breathing exercises for dyspnea compared with a control group as measured by the Borg scale.

\section{Summary}

Yoga is a mind-body intervention that comprises a wide variety of approaches, including meditation (dhyana), breathing exercises (pranayamas), optimal coping principles (swadhyaya), exercise (asanas), nourishing diet, and positive thinking. ${ }^{27,31}$ Its ability to improve symptoms such as dyspnea has only been recently studied. ${ }^{31}$ While the evidence supporting mind-body interventions for improving dyspnea is very preliminary, these interventions appear to be promising for improving the debilitating effects of dyspnea in COPD, especially dyspnea distress or anxiety and dyspnea impact. The ATS practice guidelines for dyspnea $(2012)^{2}$ concluded that there were currently insufficient data to recommend mindfulness treatment or yoga for relieving dyspnea.

\section{Cognitive-behavioral therapy}

Cognitive-behavioral therapy (CBT) is a "structured, psychological intervention in which the patient works collaboratively with the therapist to identify the types and effects of thoughts, beliefs, attributions, and interpretations on current symptoms, feeling states and/or problem areas." ${ }^{\prime 32} \mathrm{We}$ identified two CBT psychotherapy RCTs that met our inclusion criteria (see Table 3 ).

Livermore et $\mathrm{al}^{33}$ demonstrated that dyspnea anxiety (measured by the Interpretation of Breathing Problems Questionnaire [IBPQ]) was reduced after a CBT intervention at 6,12 , and 18 month follow up evaluations, but not post-intervention at 4 weeks in adults with mild to severe COPD.

However, Kunik et $\mathrm{al}^{34}$ found that CBT was no more effective than COPD education on CRQ-dyspnea and CRQmastery scores at the end of an 8-week treatment and at a 12-month follow up in male adults with moderate to very severe COPD. Both treatments were found to have small within-group effects for improving dyspnea intensity and mastery post-intervention $(P<0.01)$.

\section{Summary}

CBT is considered a primary treatment approach in national practice guidelines for relieving anxiety in diverse populations, as supported by strong evidence ${ }^{35}$ Clearly though, more research is needed on the effectiveness of CBT on dyspnea and dyspnea-related distress relief for COPD. CBT strategies have enormous potential for relieving the affective dimension of dyspnea. ${ }^{9,15,36}$ The same corticolimbic areas of the brain activated during dyspnea have been found to be altered following CBT therapy in people with anxiety disorders, with increased activity found in the anterior cingulated cortex and 


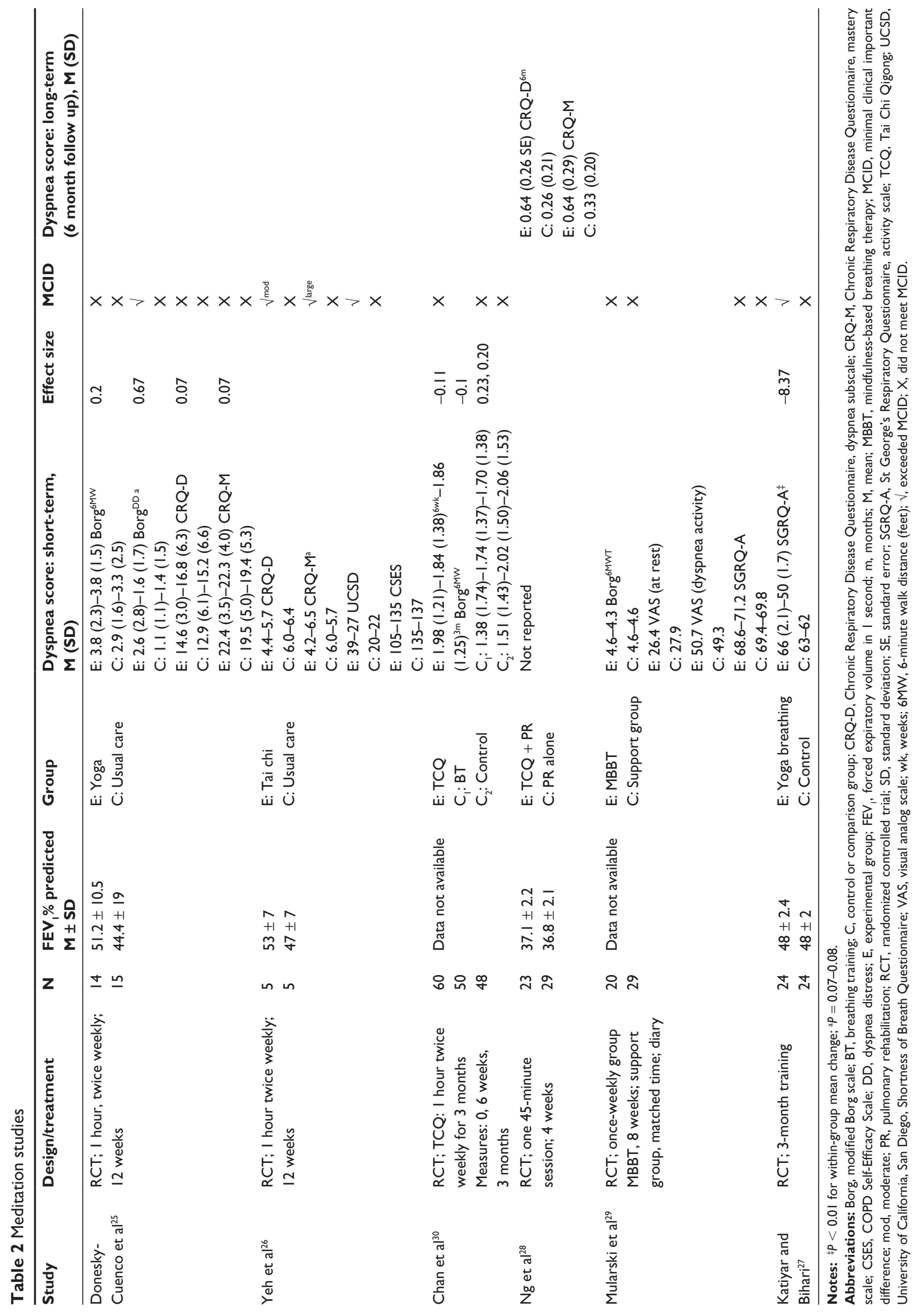




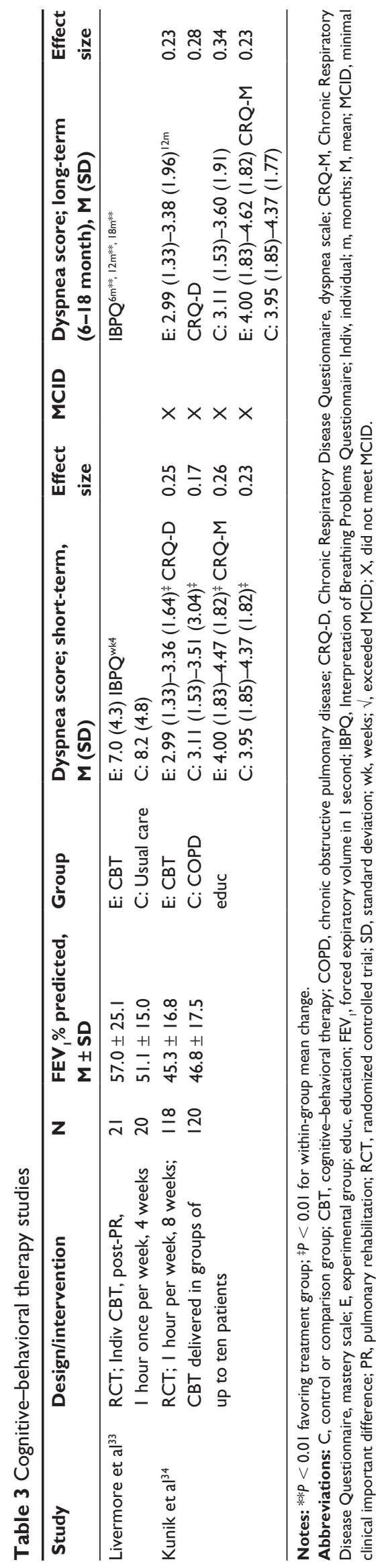

decreased activity in the amygdala. ${ }^{37}$ Preliminary evidence suggests that anxiety plays an important role in mediating the experience of dyspnea in COPD. ${ }^{15}$ More research is needed to better understand how anxiety and other affective factors impact dyspnea in order to improve dyspnea treatment. ${ }^{15,36}$ More research is needed on the effectiveness of CBT for female adults with COPD, particularly since anxiety affects women more than men with COPD. ${ }^{18,38}$ In order to measure the effectiveness of CBT on dyspnea in COPD, it may be important to measure the constructs of anxiety and dyspnearelated anxiety separately. ${ }^{39}$

\section{Slow-breathing exercises}

We identified seven studies that investigated the effects of slow-breathing exercises on dyspnea in COPD, with sample sizes between 30 and 53 participants (Table 4). Five studies evaluated patients with moderate to very severe COPD; one study with just severe COPD, and one with moderate to severe COPD. The effects of breathing exercises with biofeedback, pursed-lips breathing (PLB), diaphragmatic breathing (DB), and singing were studied.

Three RCTs found statistically significant between-group differences favoring slow-breathing exercise interventions. Yamaguti et $\mathrm{a}^{40}(\mathrm{n}=30)$ reported that the disabling impact of dyspnea in the DB group was significantly reduced compared with a control group $(P<0.05)$ as measured by the modified Medical Research Council (mMRC) scale. Improved abdominal motion with normal breathing $(P<0.001)$ and DB $(P<0.05)$ at 4 weeks, and greater diaphragmatic mobility $(P<0.001)$, were identified in the DB group. Also, using the Borg scale, Nield et $\mathrm{al}^{41}(\mathrm{n}=53)$ reported improved dyspnea at 3 months $(P<0.05)$ after a 4 -week PLB with arterial oxygen saturation $\left(\mathrm{SaO}_{2}\right)$ biofeedback intervention compared with inspiratory muscle training (IMT), expiratory muscle training (EMT), and control groups. In 2007, Nield et $\mathrm{al}^{42}$ also found decreased mean Borg dyspnea scores for patients assigned to a PLB intervention group $(P=0.05)$ at a 2 month follow up compared with comparison EMT and control groups. The dyspnea reductions were clinically significant for the PLB group at 4 weeks and 12 weeks, exceeding the MCID of five units for the University of Southern California, San Diego, Shortness Of Breath Questionnaire (UCSD SOBQ), while dyspnea worsened in the other two groups at 12 weeks.

In three additional studies, while significant differences were not found between the treatment and comparison groups, within-group differences post-intervention were clinically significant for the breathing intervention groups. ${ }^{43-45}$ 


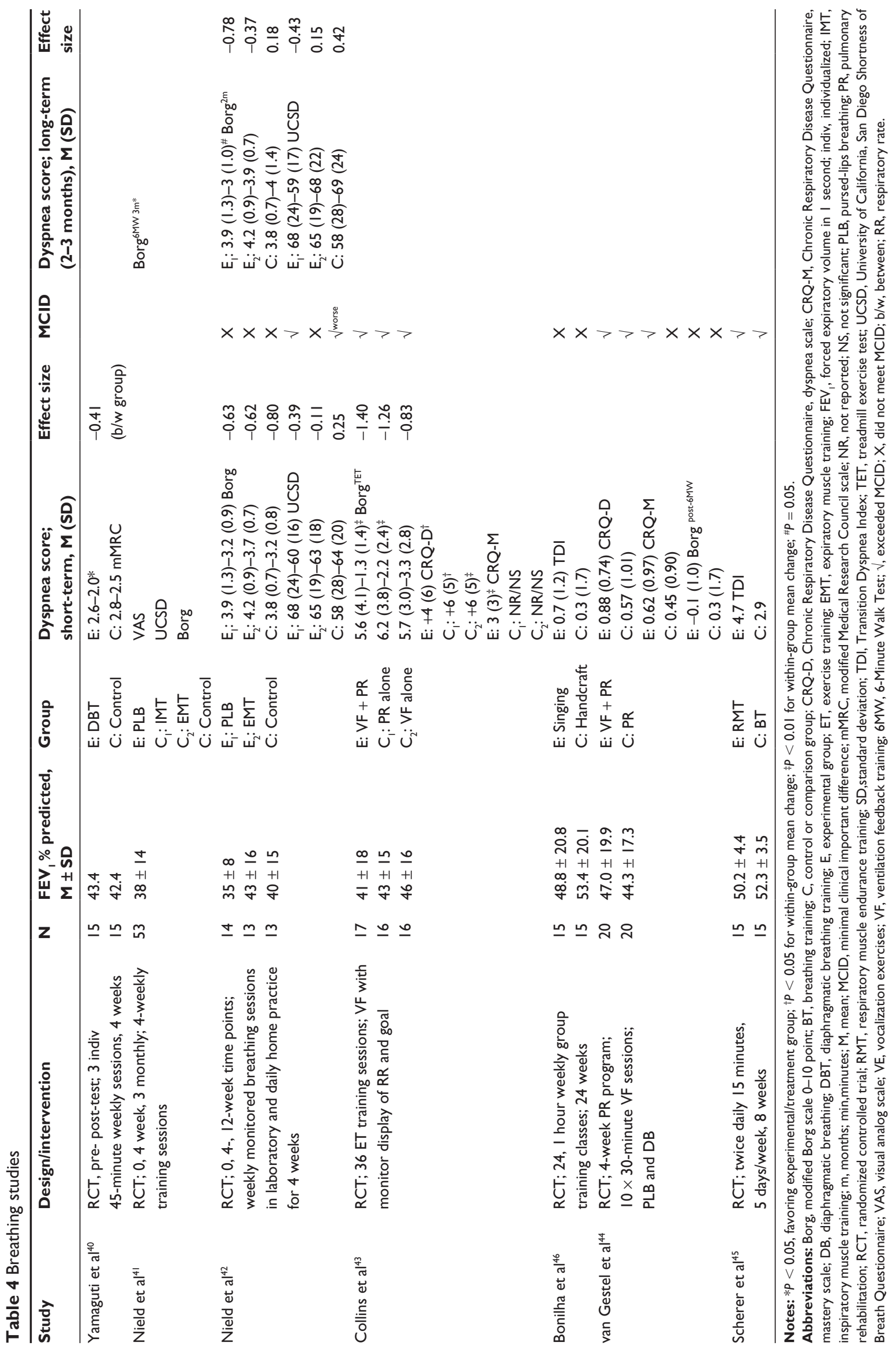


Collins et $\mathrm{al}^{43}$ found no differences for dyspnea between three groups (ET plus ventilation feedback [VF], ET alone, and VF alone) as measured by the CRQ and Borg scales $(n=49)$. A large $(-0.83$ with the Borg scale) was found for the VFalone group for dyspnea, which consisted of 36 sessions (30-35 minutes each) of training in slow breathing using a pneumotachometer interfaced to a computer with visual display and respiratory rate goal feedback, combined with lowintensity exercise. A larger dyspnea effect size (ES) was found for the ET plus VF group (ES = -1.40). Exercise-induced dynamic hyperinflation was significantly less in the ET plus VF group than in the other two groups $(P \leq 0.019)$.

van Gestel et $\mathrm{al}^{44}$ also investigated the benefits of combining breathing training with PR compared with PR alone on dyspnea in COPD $(n=40)$. While no between-group differences were identified for dyspnea as measured by the CRQ and Borg scales, the CRQ-M score improvement at discharge met the 0.5 unit MCID in the experimental group only.

Similarly, in the RCT by Scherer et al, ${ }^{45}$ the disabling dyspnea impact of both the respiratory muscle training (RMT) group and a comparison breathing training group improved as measured by the Transition Dyspnea Index (TDI). Change within the groups was clinically significant, but there was no difference between the groups $(P=0.09)$.

Finally, Bonilha et $\mathrm{al}^{46}$ compared dyspnea outcome scores following a novel singing intervention compared with a handcraft control intervention as measured by the TDI $(n=30)$. They found no differences between the groups for dyspnea.

\section{Summary}

Some evidence from small RCTs exists to support slowbreathing exercises (both PLB and DB). The types of breathing exercises studied and the protocols used varied widely between the COPD studies. Slow-breathing training was combined with PR ET in two studies. ${ }^{43,44}$

The mechanisms for improvements in dyspnea with slow-breathing exercises continue to be debated. Collins et $\mathrm{al}^{43}$ found a decrease in dyspnea to be related to a smaller end-expiratory lung volume in the VF and ET group. PLB, which reduces respiratory rate, may also improve dyspnea by reducing sympathetic activity and enhancing baroreflex efficiency in adults with COPD. Dyspnea improvements following DB in one study were found to be aided by improved abdominal motion and greater diaphragmatic mobility with normal breathing and DB at 4 weeks compared with a control group. ${ }^{40}$ Prolonged exhalations from breathing exercises and singing may increase the influence of the myelinated vagus, which decreases heart rate and improves state regulation. ${ }^{47,48}$ Both singing and PLB recruit the muscles of the face, which are linked to neural regulation of the autonomic nervous system. ${ }^{47}$ The findings of several studies support that slow-breathing training alone (without an ET effect) can reduce dyspnea. ${ }^{40,42,43}$ The American College of Chest Physicians (ACCP) consensus statement ${ }^{49}$ on the management of dyspnea with advanced lung disease recommends PLB for effective dyspnea relief.

\section{Dyspnea self-management}

Education that includes SM education is considered an important component of PR. ${ }^{22} \mathrm{SM}$ education is distinct from traditional patient education as it focuses on (1) non-didactic education based on the patient's agenda and problems identified by the patient, (2) collaborative decision making using action plans, (3) teaching problem-solving skills, and (4) increasing both self-efficacy and knowledge to promote behavior change. ${ }^{50}$ Self-efficacy in SM programs is enhanced through action plans, feedback of progress, modeling of behaviors, reinterpretation of symptoms, and social persuasion. ${ }^{51}$ Practice guidelines recommend collaborative SM education as a component of PR. ${ }^{22}$

We included five dyspnea SM studies in our review, with samples of 39-103 participants. Most of the studies evaluated participants with moderate to very severe COPD. Two of the studies found significant differences between the groups favoring experimental groups receiving both SM education and 24 CBT-based ET sessions (Table 5). ${ }^{52,53}$ Stulbarg et al ${ }^{52}$ found that the dyspnea SM and exercise group (D-SM plus 24 exercise sessions $\left[\mathrm{Ex}_{24}\right]$ ) had better CRQ dyspnea, CRQ Mastery and Borg scores than the comparison groups (D-SM alone and D-SM plus 4 exercise sessions $\left.\left[\mathrm{Ex}_{4}\right]\right)$, with mostly large ESs $(P<0.05$; ES $=-0.62$ to -1.15$)$. The dyspnea SM-alone group had small effects on CRQ dyspnea and CRQ Mastery $(0.31,0.34$, respectively), but these did not reach the MCID of 0.5 units. Similarly, the study by CarrieriKohlman et $\mathrm{al}^{53}$ found that the experimental group that received D-SM and $\mathrm{Ex}_{24}$ had better CRQ dyspnea intensity and mastery scores and Borg scores than did groups receiving D-SM alone and D-SM plus $\mathrm{Ex}_{4}$ interventions at 2 months $(P<0.01)$. They also found a reduction in the Borg dyspnea score following an incremental treadmill test at a 12-month follow up $(P<0.01)$ favoring the D-SM plus $\mathrm{Ex}_{24}$ group.

In the study by Carrieri-Kohlman et al, ${ }^{54}$ the dyspnea intensity, dyspnea distress, and dyspnea-anxiety of both intervention groups (CBT-based D-SM strategies with ET and exercise-alone groups) improved. Differences between 


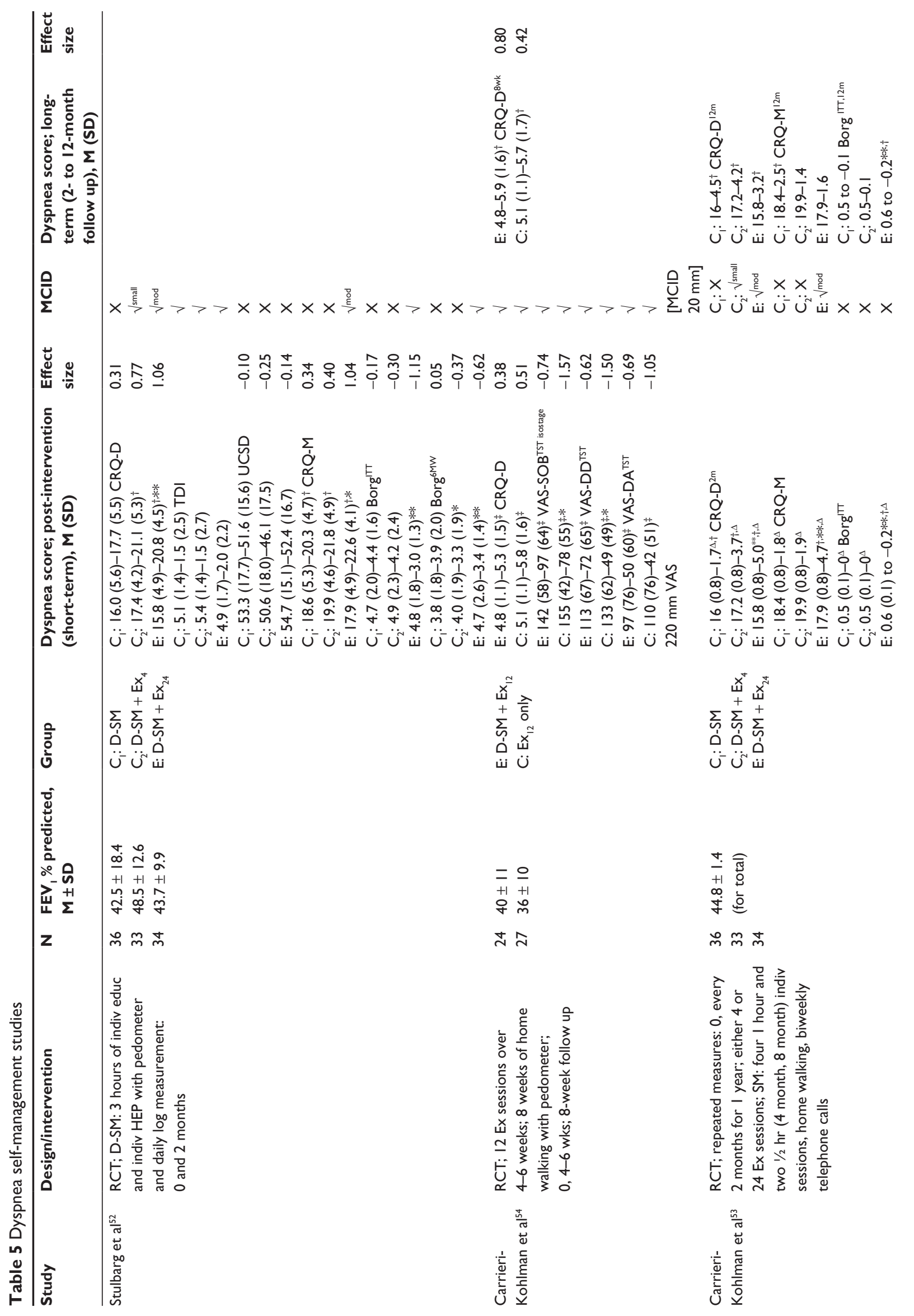




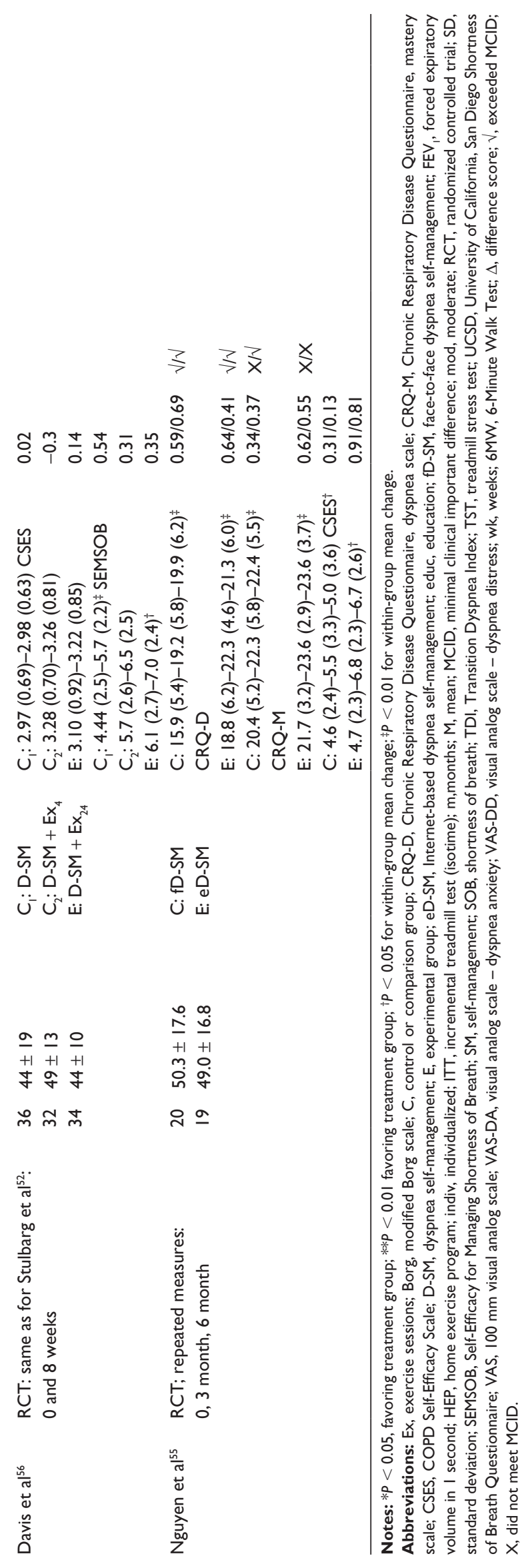

the groups $(P<0.05)$ were found for dyspnea intensity and dyspnea distress (as measured by a visual analog scale [VAS] during a treadmill stress test), favoring the comparison group receiving exercise alone. However, at a 2-month follow up, the CBT-SM plus exercise group had a larger treatment effect $(0.80)$ than the exercise alone group (0.42) for dyspnea intensity (CRQ), which was clinically significant. It may be that a CBT-SM intervention adjunctive to exercise improves dyspnea more in the long-term by promoting healthy lifestyle change compared with an exercise-alone intervention.

In an innovative study by Nguyen et $\mathrm{al}^{55}(\mathrm{n}=39)$, a faceto-face D-SM study was compared with a web-based D-SM intervention. ET was not combined with the SM intervention. No differences were found between the groups for dyspnea based on the delivery mode $(P>0.05)$. Large within-group dyspnea self-efficacy treatment effects were found for the web-based SM intervention (0.91), with effects maintained at 6 months compared with small effects $(0.31$ and 0.13 , respectively) for the face-to-face SM intervention.

\section{Summary}

Evidence supports a CBT-based COPD intervention consisting of 24 supervised treadmill exercise sessions (conceptualized as dyspnea exposure therapy) combined with D-SM education for decreasing dyspnea in the short- and long-term (at 12 months). Preliminary evidence from four studies also exists of clinically significant within-group effects for standalone D-SM programs that include an individualized home exercise program, with small to large effects for improving dyspnea. . $^{52,53,55,56}$

Web-based and telephone technology have begun to be used for delivering COPD SM interventions. Smartphones and computer technologies have enormous potential for advancing PR and D-SM programs in the future. ${ }^{57}$ Future studies should consider these delivery methods for SM interventions.

\section{Distractive auditory stimuli}

We identified three RCTs evaluating the effectiveness of music in relieving dyspnea in adults with COPD, with samples of 24-64 participants (Table 6). Participants' COPD severity was moderate to very severe in two studies and moderate to severe in one study. Two of the three studies evaluated the effects of combining music in the form of DAS with exercise. DAS or music has been conceptualized as a CBT strategy that provides desensitization of dyspnea and anxiety during physical exertion such as exercise. ${ }^{58}$ 
Table 6 Distractive auditory stimulus (DAS/music) studies

\begin{tabular}{|c|c|c|c|c|c|c|c|}
\hline Study & Design/intervention & $\mathbf{N}$ & $\begin{array}{l}\mathrm{FEV}_{1} \% \\
\text { predicted, } \\
\mathbf{M} \pm \mathrm{SD}\end{array}$ & Group & $\begin{array}{l}\text { Dyspnea score; } \\
\text { short-term, M (SD) }\end{array}$ & MCID & Effect size \\
\hline Singh & RCT; pre- post-test design; & 32 & $49 \pm 11$ & E: Music & E: $49.1(17.1)^{\text {prel }}-34.7(14.3)^{\text {postl } V A S * ~}$ & $\sqrt{ }$ & -0.91 \\
\hline \multirow{3}{*}{ et $\mathrm{al}^{61}$} & 30 minutes, twice on same day; & 32 & $54 \pm 11$ & C: PMR & C: $46(13)^{\text {prel }}-38.4(14.6)^{\text {postl }}$ & $x$ & -0.55 \\
\hline & PMR pre-recorded; & & & & E: $47(16.2)^{\text {pre2 }}-23.9(10.2)^{\text {post2 } *}$ & $\sqrt{ }$ & $-1.7 \mid$ \\
\hline & inpatient intervention & & & & C: $45.4(\text { II } .3)^{\text {pre2}}-32.5(14.4)^{\text {post2 }}$ & $\sqrt{ }$ & -1.0 \\
\hline Bauldoff & $\mathrm{RCT}$; repeated measures: & 12 & $40.4 \pm 15.6$ & E: DAS (music) & E: $60.2-52.2-44.2^{8 \mathrm{wks}} * *$ UCSD & $\sqrt{4,8 w k s}$ & \\
\hline \multirow{6}{*}{ et $\mathrm{a}^{59}$} & $0,4,8$ weeks; post-PR, home & 12 & $42.3 \pm 10.5$ & C: HEP only & C: $45.5-47 . I-53.3$ & $\sqrt{\text { worse, 8wks }}$ & \\
\hline & walking program with DAS & & & & E: $2.9(1.2)-3.3$ (I.2)-3.0 (1.2) Borg ${ }^{6 \mathrm{MW}}$ & x & E: $0.33,0.08$ \\
\hline & and electronic pedometer/log; & & & & C: $3.6(1.1)-3.2(1.1)-3.2(0.8)$ & $\mathrm{x}$ & $C:-0.36,-0.42$ \\
\hline & Music: $90-110 \mathrm{bpm}$ & & & & E: $63.8(24.2)-65.9(23.3)-67.8(19.9)$ & $\sqrt{\text { worse, 8wks }}$ & $\mathrm{E}: 0.09,0.18$ \\
\hline & & & & & SGRQ-A & & \\
\hline & & & & & C: $62.0(19.9)-61.5(17.8)-64.3(16.1)$ & $\mathrm{x}$ & $C:-0.03,0.13$ \\
\hline Bauldoff & RCT; post-PR; UET sessions & 10 & $33.8 \pm 16.3$ & $\mathrm{E}_{1}: \mathrm{UET}+\mathrm{DAS}^{\mathrm{Mod}}$ & $E_{1}: 65.8(21.8)-62.3(18.5)$ UCSD 4 wks & $\mathrm{x}$ & -0.17 \\
\hline \multirow[t]{5}{*}{ et $\mathrm{al}^{60}$} & 15 minutes, $2-3$ times/week & 10 & $41.3 \pm 17.8$ & $\mathrm{E}_{2}: \mathrm{UET}+\mathrm{DAS} S^{\text {slow }}$ & $E_{2}: 58.4(22.9)-53.9(22.3)$ & $x$ & -0.20 \\
\hline & for 4 weeks; portable music & 10 & $46.1 \pm 19.9$ & $\mathrm{C}^{2}:$ UET & C: $55.2(22.8)-54.0(16.7)$ & $x$ & -0.06 \\
\hline & & & & & $E_{1}: 78.8(10.5)-72.3$ (I6.7) SGRQ-A & $\sqrt{ }$ & -0.47 \\
\hline & & & & & $E_{2}: 77.7(15.9)-68.3(15.1)$ & $\sqrt{ }$ & -0.61 \\
\hline & & & & & C: 79.4 (I5.6)-76.8 (I5.7) & $\mathrm{x}$ & -0.17 \\
\hline
\end{tabular}

Notes: $* P<0.05$, favoring treatment group; $* * P<0.0$ I favoring treatment group.

Abbreviations: Borg, modified Borg scale; bpm, beats per minute; C, control or comparison group; DAS, distractive auditory stimuli; E, experimental group; FEV , forced expiratory volume in I second; HEP, home exercise program; M, mean; mod, moderate; MCID, minimal clinical important difference, PMR, progressive muscle relaxation; postx, post session x; PR, pulmonary rehabilitation; prex, pre session x; RCT, randomized controlled trial; SD, standard deviation; SGRQ-A, St George's Respiratory Questionnaire, activity scale; UCSD, University of California, San Diego Shortness of Breath Questionnaire; UET, upper extremity training exercises using upper body

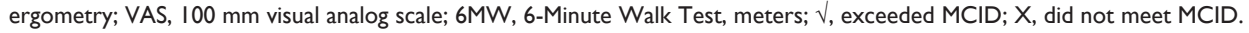

A difference was found for dyspnea with activities $(P<0.01)$ in the short term favoring the DAS intervention in a small RCT; the group difference exceeded 5.0 units MCID for the UCSD SOBQ. ${ }^{59}$ The DAS group listened to self-selected upbeat music of $90-110$ beats per minute during unsupervised home walking. Participants in both study groups (the DAS and Home Exercise Program [HEP] only groups) were given an unsupervised home walking program using a pedometer post-PR. DAS appeared to promote better tolerance of dyspnea and a greater training effect.

Bauldoff et $\mathrm{l}^{60}$ evaluated the effectiveness of combining DAS with a 4-week upper extremity (UE) training program. No differences were found for dyspnea between the three groups $(P>0.05)$. The disabling impact of dyspnea with activities (as measured by the SGRQ-A subscale) showed clinically significant reductions in the DAS groups (of greater than the MCID of 4 points) but not in the control group of UE training alone. A moderate treatment effect $(-0.61)$ was found for the slow-tempo DAS intervention (60-89 beats per minute).

Singh et $a l^{61}$ studied the effects of music compared with a progressive muscle relaxation (PMR) intervention in medically stable inpatients with COPD. Both music (selfselected, non-lyrical classical instrumental, 60-80 beats per minute) and PMR were clinically effective (exceeding the MCID) in immediately reducing dyspnea as measured by the vertical VAS. The dyspnea and anxiety improvements for the music group were higher than for the PMR group $(P<0.01)$. Both interventions showed medium to large ESs on reducing dyspnea intensity.

\section{Summary}

The three RCTs provide supporting evidence for the use of music as a CBT-based distraction strategy. A theoretical rationale for DAS or music is that it occupies the attention channels that normally carry dyspneic information. ${ }^{60}$ Music may promote desensitization to dyspnea during ET. ${ }^{58}$ By reducing dyspnea, DAS appears to promote greater exercise tolerance, (including walking distance ${ }^{59}$ and UE repetitions ${ }^{60}$ ) and positive affect, and to reduce anxiety. ${ }^{59,61}$ These outcomes are important goals of PR for patients with COPD. ${ }^{62,63}$

\section{Conclusion}

CBT and SM interventions hold promise in effectively relieving disabling sensory and affective dyspnea in COPD. Recent research shows that such interventions can enhance COPD dyspnea outcomes when used in combination with, and adjunctive to, ET. These interventions appear to improve dyspnea and counteract related emotional stress and fight-or-flight physiological and behavioral responses. CBT interventions focused specifically on dyspnea exposure and 
cognitive restructuring may be especially useful in relieving dyspnea distress and warrant further research. ${ }^{15}$ Additional clinical trials of CBT strategies are needed to provide stronger evidence of their effectiveness in relieving dyspnea with COPD. Future studies should include validated measures of both affective and sensory dyspnea to more comprehensively measure the effectiveness of dyspnea treatments.

\section{Disclosure}

The authors report no conflicts of interest in this work.

\section{References}

1. Global Initiative for Chronic Obstructive Lung Disease (GOLD). Global Strategy for the Diagnosis, Management, and Prevention of Chronic Obstructive Pulmonary Disease: Revised 2011. http://www.goldcopd. org/uploads/users/files/GOLD_Report_2011_Feb21.pdf. Accessed February 1, 2013.

2. Parshall MB, Schwartzstein RM, Adams L, et al. An official American Thoracic Society statement: update on the mechanisms, assessment, and management of dyspnea. Am J Respir Crit Care Med. 2012;185(4): 435-452.

3. Burki NK, Lee L. Mechanisms of dyspnea. Chest. 2010;138(5): 1196-1201.

4. Evans KC. Cortico-limbic circuitry and the airways: insights from functional neuroimaging of respiratory afferents and efferents. Biol Psychol. 2010;84:13-25.

5. De Peuter S, van Diest I, Lemaigre V, Verleden G, Demedts M, Van den Bergh O. Dyspnea: the role of psychological processes. Clin Psychol Rev. 2004;24:557-581.

6. Kessler R, Partridge MR, Miravitlles M, et al. Symptom variability in patients with severe COPD: a pan-European cross-sectional study. Eur Respir J. 2011;37:264-272.

7. Davenport PW, Vovk A. Cortical and subcortical central neural pathways in respiratory sensations. Respir Physiol Neurobiol. 2009;167:72-86.

8. Lansing RW, Gracely RH, Banzett RB. The multiple dimensions of dyspnea: review and hypotheses. Respir Physiol Neurobiol. 2009;167: 53-60.

9. O’Donnell DE, Banzett RB, Carrieri-Kohlman V, et al. Pathophysiology of dyspnea in chronic obstructive pulmonary disease: a roundtable. Proc Am Thorac Soc. 2007;4:145-168.

10. Higashimoto Y, Honda N, Yamagata T, et al. Activation of the prefrontal cortex is associated with exertional dyspnea in chronic obstructive pulmonary disease. Respiration. 2011;82(6):492-500.

11. Schön D, Dahme B, von Leupoldt A. Associations between the perception of dyspnea, pain, and negative affect. Psychophysiology. 2008;45: 1064-1067.

12. von Leupoldt A, Ambruzsova R, Nordmeyer S, Jeske N, Dahme B. Sensory and affective aspects of dyspnea contribute differentially to the Borg scale's measurement of dyspnea. Respiration. 2006;73:762-768.

13. Peiffer C. Dyspnea and emotion: what can we learn from functional brain imaging? Am J Respir Crit Care Med. 2008;177:937-939.

14. Lange P, Marott JL, Vestbo J, et al. Prediction of the clinical course of chronic obstructive pulmonary disease, using the new GOLD classification: a study of the general population. Am J Respir Crit Care Med. 2012;186(10):975-981.

15. Simon NM, Weiss AM, Kradin R, et al. The relationship of anxiety disorders, anxiety sensitivity and pulmonary dysfunction with dyspnea-related distress and avoidance. J Nerv Ment Dis. 2006;194(12):951-957.

16. Maurer J, Rebbapragada V, Borson S, et al. ACCP Panel on Anxiety and Depression in COPD. Anxiety and depression in COPD: current understanding, unanswered questions, and research needs. Chest 2008;134(Suppl 4):43S-56S.
17. Kunik ME, Roundy K, Veazey C, et al. Surprisingly high prevalence of anxiety and depression in chronic breathing disorders. Chest. 2005;127: $1205-1211$.

18. Laurin C, Lavoie KL, Bacon SL, et al. Sex differences in the prevalence of psychiatric disorders and psychological distress in patients with COPD. Chest. 2007;132(1):148-155.

19. Wagena EJ, Arrindell WA, Wouters EFM, van Schayck CP. Are patients with COPD psychologically distressed? Eur Respir J. 2005;26: 242-248.

20. Raupach T, Bahr F, Herrmann P, et al. Slow breathing reduces sympathoexcitation in COPD. Eur Respir J. 2008;32:387-392.

21. Tug T, Terzi SM, Yoldas TK. Relationship between the frequency of autonomic dysfunction and the severity of chronic obstructive pulmonary disease. Acta Neurol Scand. 2005;112:183-188.

22. Ries AL, Bauldoff GS, Carlin BW, et al. Pulmonary rehabilitation: joint ACCP/AACVPR evidence-based practice guidelines. Chest. 2007;131(Suppl 5):4S-42S,

23. Zuwallack R. The nonpharmacologic treatment of chronic obstructive pulmonary disease: advances in our understanding of pulmonary rehabilitation. Proc Am Thorac Soc. 2007;4:549-553.

24. Nici L, Donner C, Wouters E, et al. American Thoracic Society/ European Respiratory Society statement on pulmonary rehabilitation. Am J Respir Crit Care Med. 2006;173:1390-1413.

25. Donesky-Cuenco D, Nguyen HQ, Paul S, Carrieri-Kohlman V. Yoga therapy decreases dyspnea-related distress and improves functional performance in people with chronic obstructive pulmonary disease: a pilot study. J Altern Complement Med. 2009;15(3):225-234.

26. Yeh GY, Roberts DH, Wayne PM, Davis RB, Quilty MT, Phillips RS Tai chi exercise for patients with chronic obstructive pulmonary disease: a pilot study. Respir Care. 2010;55(11):1475-1482.

27. Katiyar SK, Bihari S. Role of pranayama in rehabilitation of COPD patients: a randomized controlled study. Indian J Allergy Asthma Immunol. 2006;20(2):98-104.

28. Ng BH, Tsang HW, Jones AY, So CT, Mok TY. Functional and psychosocial effects of health qigong in patients with COPD: a randomized controlled trial. J Altern Complement Med. 2011;17(3):243-251.

29. Mularski RA, Munjas BA, Lorenz KA, et al. Randomized controlled trial of mindfulness-based therapy for dyspnea in chronic obstructive lung disease. J Altern Complement Med. 2009;15(10):1083-1090.

30. Chan AW, Lee A, Suen LK, Tam WW. Tai chi Qigong improves lung functions and activity tolerance in COPD clients: a single blind, randomized controlled trial. Complement Ther Med. 2011;19(1): $3-11$.

31. Carson JW, Carson KM, Jones KD, Bennett RM, Wright CL, Mist SD. A pilot randomized controlled trial of the Yoga of Awareness program in the management of fibromyalgia. Pain. 2010;151(2): 530-539.

32. Cafarella PA, Effing TW, Usmani ZA, Frith PA. Treatments for anxiety and depression in patients with chronic obstructive pulmonary disease: a literature review. Respirology. 2012;17:627-638.

33. Livermore N, Sharpe L, McKenzie D. Prevention of panic attacks and panic disorder in COPD. Eur Respir J. 2010;35(3):557-563.

34. Kunik ME, Veazey C, Cully JA, et al. COPD education and cognitive behavioral therapy group treatment for clinically significant symptoms of depression and anxiety in COPD patients: a randomized controlled trial. Psychol Med. 2008;38(3):385-396.

35. Butler AC, Chapman JE, Forman EM, Beck AT. The empirical status of cognitive-behavioral therapy: a review of meta-analyses. Clin Psychol Rev. 2006;26:17-31.

36. Von Leupoldt A, Dahme B. Cortical substrates for the perception of dyspnea. Chest. 2005;128(1):345-354.

37. Clark DA, Beck AT. Cognitive theory and therapy of anxiety and depression: convergence with neurobiological findings. Trends Cogn Sci. 2010;14(9):418-424.

38. Divo M, Cote C, de Torres JP, et al. Comorbidities and risk of mortality in patients with chronic obstructive pulmonary disease. Am J Respir Crit Care Med. 2012;186(2):155-161. 
39. Norweg A, Ni P, Garshick E, O'Connor G, Wilke K, Jette AM. A multidimensional computer adaptive test approach to dyspnea assessment. Arch Phys Med Rehabil. 2011;92:1561-1569.

40. Yamaguti WP, Claudino RC, Neto AP, et al. Diaphragmatic breathing training program improves abdominal motion during natural breathing in patients with chronic obstructive pulmonary disease: a randomized controlled trial. Arch Phys Med Rehabil. 2012;93(4):571-577.

41. Nield M, Soo Hoo G, Roper J, Santiago S. Pursed-lips breathing decreases dyspnea and improves health-related quality of life in 4-group randomized, controlled study [abstract]. Chest. 2004;126(4_MeetingAbstracts):805S.

42. Nield MA, Soo Hoo GW, Roper JM, Santiago S. Efficacy of pursed-lips breathing: a breathing pattern retraining strategy for dyspnea reduction. J Cardiopulm Rehabil Prev. 2007;27(4):237-244.

43. Collins EG, Langbein WE, Fehr L, et al. Can ventilation-feedback training augment exercise tolerance in patients with chronic obstructive pulmonary disease? Am J Respir Crit Care Med. 2008;177(8):844-852.

44. van Gestel AJ, Kohler M, Steier J, Teschler S, Russi EW, Teschler H. The effects of controlled breathing during pulmonary rehabilitation in patients with COPD. Respiration. 2012;83(2):115-124.

45. Scherer TA, Spengler CM, Owassapian D, Imhof E, Boutellier U. Respiratory muscle endurance training in chronic obstructive pulmonary disease: impact on exercise capacity, dyspnea, and quality of life. $\mathrm{Am}$ J Respir Crit Care Med. 2000;162:1709-1714.

46. Bonilha AG, Onofre F, Vieira ML, Prado MY, Martinez JA. Effects of singing classes on pulmonary function and quality of life of COPD patients. Int J Chron Obstruct Pulmon Dis. 2009;4:1-8.

47. Porges SW. The Polyvagal Theory: Neurophysiological Foundations of Emotions, Attachment, Communication, and Self-Regulation. New York: WW Norton and Co; 2011.

48. Thayer JF, Lane RD. Claude Bernard and the heart-brain connection: further elaboration of a model of neurovisceral integration. Neurosci Biobehav Rev. 2009;33:81-88.

49. Mahler DA, Selecky PA, Harrod CG, et al. American College of Chest Physicians consensus statement on the management of dyspnea in patients with advanced lung or heart disease. Chest. 2010;137(3): 674-691.

50. Bodenheimer T, Lorig K, Holman H, Grumbach K. Patient selfmanagement of chronic disease in primary care. JAMA. 2002;288: $2469-2475$

51. Lorig KR, Ritter P, Stewart AL, et al. Chronic disease self-management program: 2-year health status and health care utilization outcomes. Med Care. 2001;39(11):1217-1223.

52. Stulbarg MS, Carrieri-Kohlman V, Demir-Deviren S, et al. Exercise training improves outcomes of dyspnea self-management program. J Cardiopulm Rehabil. 2002;22(2):109-121.

53. Carrieri-Kohlman V, Nguyen HQ, Donesky-Cuenco D, Demir-Deviren S, Neuhaus J, Stulbarg MS. Impact of brief or extended exercise training on the benefit of a dyspnea self-management program in COPD. J Cardiopulm Rehabil. 2005;25(5):275-284.

54. Carrieri-Kohlman V, Gormley JM, Douglas MK, Paul SM, Stulbarg MS. Exercise training decreases dyspnea and the distress and anxiety associated with it. Monitoring alone may be as effective as coaching. Chest. 1996;110(6):1526-1535.

55. Nguyen HQ, Donesky-Cuenco D, Wolpin S, et al. Randomized controlled trial of an internet-based versus face-to-face dyspnea selfmanagement program for patients with chronic obstructive pulmonary disease: pilot study. J Med Internet Res. 2008;10(2):e9.

56. Davis AH, Carrieri-Kohlman V, Janson SL, Gold WM, Stulbarg MS. Effects of treatment on two types of self-efficacy in people with chronic obstructive pulmonary disease. J Pain Symptom Manage. 2006;32(1): 60-70.

57. Riley WT, Rivera DE, Atienza AA, Nilsen W, Allison SM, Mermelstein R. Health behavior models in the age of mobile interventions: are our theories up to the task? Transl Behav Med. 2011;1: $53-71$.
58. Haas F, Salazar-Schicchi J, Axen K. Desensitization to dyspnea in chronic obstructive pulmonary disease. In: Casaburi R, Petty TL, editors. Principles and Practice of Pulmonary Rehabilitation. Philadelphia: WB Saunders Inc; 1993:241-251.

59. Bauldoff GS, Hoffman LA, Zullo TG, Sciurba FC. Exercise maintenance following pulmonary rehabilitation: effect of distractive stimuli. Chest. 2002;122(3):948-954.

60. Bauldoff GS, Rittinger M, Nelson T, Doehrel J, Diaz PT. Feasibility of distractive auditory stimuli on upper extremity training in persons with chronic obstructive pulmonary disease.J Cardiopulm Rehabil.2005;25(1): $50-55$.

61. Singh VP, Rao V, Prem V, Sahoo RC, Keshav Pai K. Comparison of the effectiveness of music and progressive muscle relaxation for anxiety in COPD: a randomized controlled pilot study. Chron Respir Dis. 2009;6(4):209-216.

62. von Leupoldt A, Taube K, Schubert-Heukeshoven S, Magnussen H, Dahme B. Distractive auditory stimuli reduce the unpleasantness of dyspnea during exercise in patients with COPD. Chest. 2007;132: $1506-1512$.

63. Bauldoff GS. Music: more than just a melody. Chron Respir Dis. 2009;6(4):195-197.

64. Ries AL. Minimally clinically important difference for the UCSD Shortness of Breath Questionnaire, Borg Scale, and Visual Analog Scale. COPD. 2005;2:105-110.

65. Giardino ND, Chan L, Borson S. Combined heart rate variability and pulse oximetry biofeedback for chronic obstructive pulmonary disease: preliminary findings. Appl Psychophysiol Biofeedback. 2004;29(2): 121-133.

66. De Peuter S, Janssens T, Van Diest I, et al. Dyspnea-related anxiety: the Dutch version of the Breathlessness Beliefs Questionnaire. Chron Respir Dis. 2011;8(1):11-19.

67. Guyatt GH, Berman LB, Townsend M, Pugsley SO, Chambers LW. A measure of quality of life for clinical trials in chronic lung disease. Thorax. 1987;42:773-778.

68. Jaeschke R, Singer J, Guyatt GH. Measurement of health status: ascertaining the minimal clinically important difference. Control Clin Trials. 1989;10:407-415

69. Redelmeier DA, Guyatt GH, Goldstein RS. Assessing the minimal important difference in symptoms: a comparison of two techniques. J Clin Epidemiol. 1996;49:1215-1219.

70. Wigal JK, Creer TL, Kotses H. The COPD Self-Efficacy Scale. Chest. 1991;99:1193-1196.

71. Norweg A, Jette Am, Ni P, Whiteson J, Kim M. Outcome measurement for COPD: reliability and validity of the Dyspnea Management Questionnaire. Respir Med.2011;105(3):442-453.

72. Migliore Norweg A, Whiteson J, Demetis S, Rey M. A new functional status outcome measure of dyspnea and anxiety for adults with lung disease: the dyspnea management questionnaire. J Cardiopulm Rehabil. 2006;26:395-404.

73. Sutton K, Cooper M, Pimm J, Wallace L. Anxiety in chronic obstructive pulmonary disease: the role of illness specific catastrophic thoughts. Cognit Ther Res. 1999;23(6):573-585.

74. Lorig K, Stewart A, Ritter P, Gonzalez VM, Laurent D, Lynch J. Outcome Measures for Health Education and Other Health Care Interventions. Thousand Oaks: Sage Publications; 1996.

75. Schünemann HJ, Griffith L, Jaeschke R, Goldstein R, Stubbing D, Guyatt GH. Evaluation of the minimal important difference for the feeling thermometer and the St George's Respiratory Questionnaire in patients with chronic airflow obstruction. J Clin Epidemiol. 2003;56: $1170-1176$

76. Mahler DA, Witek TJ Jr. The MCID of the transition dyspnea index is a total score of one unit. COPD. 2005;2:99-103.

77. Kupferberg DH, Kaplan RM, Slymen DJ, Ries AL. Minimally clinically important difference for the UCSD Shortness of Breath Questionnaire. J Cardiopulm Rehabil. 2005;25:370-377. 
International Journal of COPD

\section{Publish your work in this journal}

The International Journal of COPD is an international, peer-reviewed journal of therapeutics and pharmacology focusing on concise rapid reporting of clinical studies and reviews in COPD. Special focus is given to the pathophysiological processes underlying the disease, intervention programs, patient focused education, and self management protocols.

This journal is indexed on PubMed Central, MedLine and CAS. The manuscript management system is completely online and includes a very quick and fair peer-review system, which is all easy to use. Visit $\mathrm{http}: / /$ www.dovepress.com/testimonials.php to read real quotes from published authors.

Submit your manuscript here: http://www.dovepress.com/international-journal-of-copd-journal 